\title{
Behavioral Objects: The Rise of the Evocative Machines
}

\author{
Florent Levillain, Elisabetta Zibetti \\ Laboratoire CHART-LUTIN (Cognition Humaine \& Artificielle EA 4004, \\ Université Paris 8, EPHE Paris; Cité des Sciences et de l'Industrie, Paris), \\ (Saint Denis - Cedex 02, France)
}

\begin{abstract}
A new race of artifacts comes equipped with behavioral properties. Those properties transmute the very nature of the object, granting it a life of its own and a special status that stems from the psychological attributions humans naturally produce when confronted by autonomous movements. This article examines what makes behavioral objects special in terms of the psychological properties they evoke in an observer. We look into the notion of behavior and evaluate to what extent the concept of anthropomorphism is a valid construct when considering the behavior of artificial objects. Based on recent research in cognitive psychology, we propose a framework to conceptualize the way people infer psychological attributes from movement, and the way it applies to behavioral objects.
\end{abstract}

Keywords: human-robot interaction, behavior, non-anthropomorphic robot, agency

\section{Introduction}

Three grand pianos move in a room. As they evolve calmly in an apparently random fashion, they sometimes collide with each other, promptly changing direction in response to the contact of their congeners. They move suddenly, pivot, stay immobile for a while, and sometimes seem to chase each other. This emergent choreography attracts people around the pianos. Some join in the dance, curious to examine closely each piano's demeanor; some remain more withdrawn and contemplate the ballet from a distance. This scene describes an installation created in 2014 by the French artist Céleste Boursier-Mougenot that we had the opportunity to study as psychologists interested in the interactions prompted by these animated objects (Levillain, Zibetti, \& Lefort, 2016). This installation is an artistic act that breathes life into the inanimate and reinvigorates our relationship to mundane object. It constitutes also a reminder of the recent transformations in the robotic landscape, with technological artifacts acquiring a partial autonomy as the result of the dissemination of embedded technologies (e.g., cheap sensors, motors, boards, microprocessors, etc.). Finally, it is a testimony to Human-Robot Interaction (HRI) problematics in their simplest form: from the way an object moves in space, how to create a connection with a human being?

People working in Interaction Design (IxD), Human-Computer Interaction (HCI), and HRI are now engaged in a prospective analysis of the potential interactions associated with new forms of domestic and social robotics (Auger, 2014; Forlizzi, 2007; Forlizzi \& DiSalvo, 2006; Joosse, Sardar, Lohse \& Evers, 2013). A diverse range of technological artifacts now come equipped with abilities to self-regulate, move autonomously, detect and anticipate malfunctions, communicate, etc. These robotic artifacts are sometimes an enhanced version of already existing artifacts, such as a car, an elevator, a lawn mower, or a vacuum cleaner, or sometimes an altogether different form of artifact designed for an original purpose, such as in the domain of speculative design (e.g., Dunne \& Raby, 2007). These artifacts have in common a certain ability to sense their environment, even in a very crude fashion, and to act on this information by modifying their behavior. What is more, these objects tend to impress on those observing them an impression of aliveness, and may create an affective bond that would not exist if these objects remained inert.

Authors retain copyright and grant the Journal of Human-Robot Interaction right of first publication with the work simultaneously licensed under a Creative Commons Attribution License that allows others to share the work with an acknowledgement of the work's authorship and initial publication in this journal.

Journal of Human-Robot Interaction, Vol. 6, No. 1, 2017, Pages 4-24, DOI 10.5898/JHRI.6.1.Levillain 
What makes those objects special? Where is the sense of aliveness they express coming from? This appearance of vitality will tend to remain mysterious and intangible if not confronted with the adequate conceptual tools. These tools reside in the domain of cognitive psychology, and more specifically, in the domain of the understanding of action (also called "perception of action," "perception of animacy," or "perception of agency"). We think roboticists would benefit from knowing the movement cues that the human brain considers when producing a spontaneous interpretation of an observed behavior. This is a knowledge that may allow to channel the social presence of a robot, to design interesting interactions that may facilitate acceptance of robots, and generally to consider behavior as a matter to design with, independently of a humanoid or zoomorphic appearance.

This article is written from the point of view of psychologists and will not tackle technical issues regarding the implementation of the movements or movement patterns we describe. We elaborate from a minimalistic approach, which is justified by the fact that we consider the basic principles that regulate the perception and understanding of action, and through which a movement becomes meaningful. Our objective is to consider the notion of behavior in robotics through the lens of unsophisticated, non-humanoid or zoomorphic robotic artifacts (which we will call behavioral objects). We will reflect on the possibility to dissociate the behavior from the overall morphology of the robotic artifact and consider behavior as a vehicle of empathic and emotional bonds beyond the constraints imposed by the form. We will analyze the notion of anthropomorphism as a concept that we think is conflating important distinctions with respect to the psychological inferences people make when confronted by animated entities. Finally, we will provide a cognitive framework to index the most important movement patterns and their associated interpretations that result in the perception of a certain behavioral complexity in a robotic artifact.

\section{Designing Objects With Behavior in Mind}

In the areas of emotional design (Norman, 2007, 2010) and affective IxD (Khalid, 2006; Rogers, Sharp, \& Preece, 2015), for which the affective environment surrounding a product is crucial to its success (Demirbilek \& Sener, 2003), robotic artifacts designers no longer only consider a product's physical aspects but also the intangible aspects associated with certain behavioral qualities (Bianchini, Bourganel, Quinz, Levillain, \& Zibetti, 2015). Ju \& Takayama (2009) showed, for instance, that something so mundane as an automatic door can be improved by taking into account the subtle communicative cues that people are sensitive to when interacting, making the doors gesture toward a passerby to invite him to enter. A door making a gesture is not actually a door waving its hand; it is a door augmented by a computational system that opens and closes in response to relevant input coming from a human person. What matters here is the communicative intention, which is recognized by a human as such, providing it conforms to certain patterns interpretable as intentional movements. Certain robotic artifacts - that we call behavioral objects ${ }^{l}$ - while not resembling humans or animals, are able to carry spatial transformations that can be interpreted as actions executed toward a goal, possibly motivated, and possibly intelligent. In light of the behavioral properties displayed by these artifacts, we may consider them not just in terms of the function they fulfill, but as animated beings with a certain level of perceived autonomy and an identity proportional to the degree to which their output is intelligible in terms of intentional actions.

Because of their abilities to produce apparent spontaneous transformations (see Box 1), behavioral objects cause users to adopt different interpretation strategies to those they would use for objects with functions that are not interactive or behavioral. The way that robotic artifacts produce behaviors spontaneously encourages users to attribute qualities of a psychological nature to them: These objects appear to have intentions, emotions, beliefs, and even personality traits.

The Impatient Toaster (Burneleit, Hemmert, \& Wettach, 2009) is an example of an object with an ordinary appearance, for which the addition of behavioral functions significantly enriches its functionality. In order to attract attention, the Impatient Toaster vibrates in a nervous way at regular intervals. These nervous vibrations subside once the toaster has been "fed," and start again when the bread has been toasted; the toast has to be removed in order to calm the toaster down again until its next fit of impatience. This simple behavior produces interesting effects on the

\footnotetext{
${ }^{1}$ See section 4 for a definition of the notion of behavior and behavioral objects.
} 
Levillain and Zibetti, Behavioral Objects

Box $1 . \mathbf{3 6 0}^{\circ}$ Presence by Jeppe Hein (2002) http://www.youtube.com/watch?v=95RZUuA-tJI
A $70 \mathrm{~cm}$ diameter steel ball starts rolling when a visitor enters the gallery where it is exhibited. The massive ball has no fixed
trajectory and collides with the gallery walls, gradually destroying the fittings and leaving a dark trail throughout the room.
The visitor has no apparent control over the ball's movements and can only make its violent impulses stop by exiting the
gallery.
An important characteristic of this behavioral artwork is spontaneity of movement. The object moves by itself, without any
external aid and without visible recourse to any mechanism capable of explaining its trajectory. The spontaneous production
of movement is perhaps the first indication of a living presence. It establishes a particular psychological attitude on the part
of the spectator, who attempts to assign an intelligible character to the transformations that are being witnessed. The spectator
is denied a sense of mastery that comes with the possibility to predict a system performance, and the apparent autonomy of
the ball forces them to consider its subjectivity. Moreover, in $360^{\circ}$ Presence, the random movement of the ball gives the
object the appearance of a being with an indeterminate will, placing the visitor in the uncomfortable position of not being
able to work out what is causing the ball's behavior.

status given to the object by users: some users talk to it, while others try to touch it to calm it down, suggesting the empathic reactions usually reserved for people or pets. The object's autonomy is demonstrated here by it bursting into sudden movements; the unexpected nature of these movements requires an explanation using psychological attributes: "it's started to move all of a sudden because it's hungry." The fact that one is able to affect these movements by "feeding" the toaster opens up the possibility of an interaction, albeit a rudimentary one. The practical relationship with the object is coupled with an emotional one, which is mediated by a type of attribution that is dependent on how the behavior is interpreted.

This example of a robotic artifact highlights the current trend for designers to embellish objects with behavioral functions in order to provide users with increasingly intuitive ways of interacting with them. Products can no longer merely be functional but must also elicit and sustain emotional responses (Desmet, 2003a, 2003b; Dunne \& Raby 2001), particularly through the interactions they encourage with users (Boehner, DePaula, Dourish, \& Sengers, 2007; Wright \& McCarthy, 2008). Design is therefore no longer solely a process of inventing physical forms to produce and facilitate action (Gibson, 1979; Norman, 1990, 1999); it now needs to promote an aesthetic of interaction, by creating patterns of behavior and feedback while also providing an engaging and interactive embodied experience (Bilda, Candy, \& Edmonds, 2008; Djajadiningrat, Wensveen, Frens, Overbeeke, 2004; Hummels, Overbeeke, \& Klooster, 2007). Indeed, a new type of relationship with, and experience of, objects is created through this behavior and feedback, with objects becoming companions. The Impatient Toaster is not only designed to toast bread but also to engage the user in the good habit of eating regularly. In a similar way, the Never Hungry Caterpillar (Laschke, Hassenzahl, \& Diefenbach, 2012), which produces a behavior suggesting it is in pain when the user leaves the TV on standby, uses an empathic relationship to remind the user to self-regulate energy use (by turning off the TV).

\section{Behavioral Vs. Form Realism}

When assessing the behavior of a robot, its appearance and the way it moves constitute two sources of inferences that may work in unison or may conflict, depending on the degree of integration between the computations implemented, the robot's morphology, the material from which it is made, and the movements patterns scripted. As suggested by Hoffman \& Ju (2014), although the robot's appearance "sets the context for interaction," the robot's movement "can support action coordination, communicate internal states, and also has its own emotional impact" (pp. 1-2). These authors enjoin to design robots with expressivity in mind, meaning that in the process of conceiving a robot, movement must be considered early as a way to convey the robot's characteristics, its own way of being in the world, its purpose, and its capabilities. 
Levillain and Zibetti, Behavioral Objects

Box 2. The Table by Max Dean and Raffaella d'Andrea (1984) https://www.youtube.com/watch?v=M6DItTI3oOM
At first view, this is just an ordinary table, but when a visitor enters the gallery in which it is exhibited, it suddenly starts to
move toward them. It stops near the visitor and reacts to their movements, following them if they move away or moving back
if the visitor approaches the table. The table moves slowly and appears to have little control over its movements, giving the
impression of a heavy, clumsy animal.
Max Dean and Raffaello d'Andrea's table is an example of a second type of behavioral element used by creators of behavioral
pieces to introduce an impression of a living presence; this impression is strengthened here by the table's apparent
intentionality. The interactive nature of the installation is the essential element here that shapes the types of psychological
attributions made by the visitor. The table initiates the interaction by moving toward the visitor then reacts in ways that
depend on the visitor's movements, as if its behavior were based upon the visitor's. Unlike the metallic ball described in Box
1, the table is not a wild, undisciplined being. Because of its reactions to visitors movements, it establishes itself in the
exhibition space as a social object, affected by the visitor's presence and inviting the latter to adopt a particular attitude, for
example by playing with the table or by trying to avoid it.

This design approach, centered on the intrinsic qualities of the movements, illustrates a tendency to depart from the general assumption that a more familiar appearance is desirable to elicit more proximity with a robot. While a forceful march is engaged toward the creation of highly anthropomorphic or zoomorphic robots, somewhat dissonant voices advise to escape the rush for morphological mimicry, for at least two reasons. First, the uncanny valley phenomenon (Mori, 1970) often thwarts the efforts to make robots more socially acceptable. Humanoid robots sometimes provoke fear, disgust, or a general feeling of strangeness (Gray \& Wegner, 2012; MacDorman \& Ishiguro, 2006). A general dissonance between the (humanlike) appearance of the robot and its (clunky) behavior may be central to the feeling of uncanniness (Saygin, Chaminade, Ishiguro, Driver, \& Frith, 2012). Second, the development of soft robotics (e.g., Brown et al., 2010; Mazzolai, Margheri, Cianchetti, Dario, \& Laschi , 2012), with its emphasis on morphological properties and material characteristics, encourage to experiment beyond the traditional template that is the human body, producing soft and deformable robots that look like nothing else yet are susceptible to evoke the harmoniousness with which living beings are moving.

The previous examples of behavioral objects have presented objects with familiar functionalities (see Section 2, also Boxes $2 \& 3$ ), as well as objects with no apparent functionality (see Box 1), all displaying a certain behavioral complexity that emanates from motion patterns. In light of the expressivity they manifest, it is tempting to assume that their behavioral qualities are the primary responsible for a form of social presence (defined as the "sense of being with another"; Biocca, Harms, \& Burgoon, 2003) they impress upon a human audience. We know that humans are extremely sensitive to movements and can use sole kinematics to infer properties of objects (Runeson \& Frykholm, 1983). From point-light animations representing markers at the joints of the body, people readily discern, for instance, the identity of a person (Cutting \& Kozlowski, 1977), the emotional implication of an action (Clarke et al., 2005), or they can estimate the weight of lifted object from observing the lifting motion alone (Bingham, 1993). In the domain of digital, virtual environments, the social presence of virtual avatars is strongly dependent on a certain behavioral realism (Bailenson, Yee, \& Merget, 2006), even more so than their form realism (Garau, 2003). In this case, behavioral realism amounts to the implementation of reactions contingent on the user's actions (e.g., tracking the user's face to adjust the robot's gaze direction; certain social routines such as greeting or turn taking in a conversation). In the domain of HRI, numerous robotic platforms (e.g., Kismet, Paro, eMuu,) implement realistic behaviors at the expense of a humanoid, or even zoomorphic, appearance. These platforms are successful at establishing a relationship of familiarity and empathy, providing they respect certain minimal conditions that Damiano, Dumouchel, \& Lehman (2014) define as bodily embodiment, autonomous movement, and dialoging skills.

In our view, the strongest evidence that behavior can promote a form of social presence despite a lack of complex features comes from experimental studies investigating the perception of animacy and agency, that is, the 
Levillain and Zibetti, Behavioral Objects

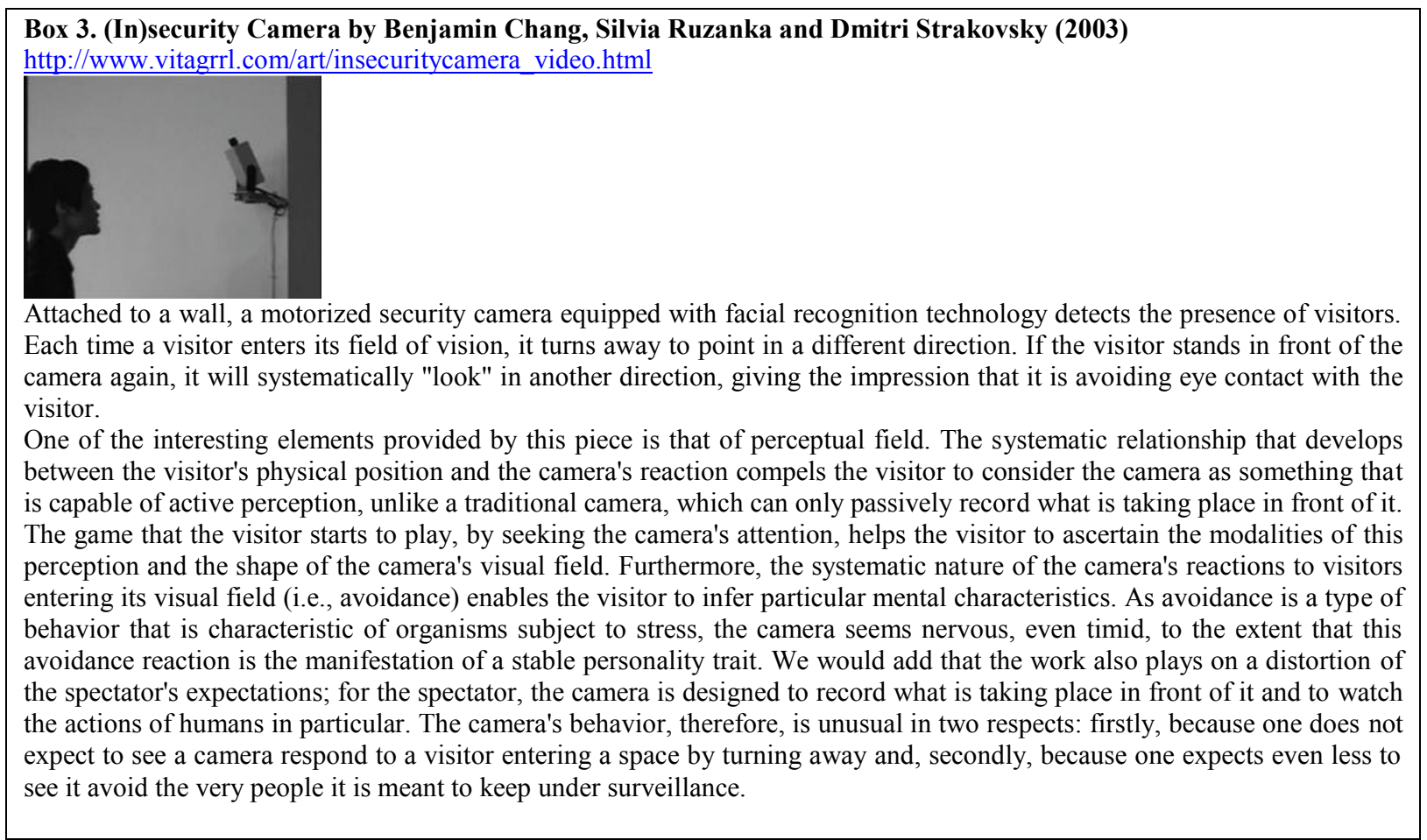

way people spontaneously attribute goals and intentions to abstract moving objects displayed on a screen. In a pioneering experiment dating back in history, Heider and Simmel (1944) observed the reaction of people presented with a short film depicting three geometric figures: two circles and a triangle, moving in different ways. In spite of the total absence of context or any recognizable figures, observers would spontaneously produce detailed narratives, bestowing intentions and desires on the moving objects. The Heider \& Simmel's experiment, as well as many similar experiments conducted later (e.g., Castelli, Happé, Frith, \& Frith, 2000; Kassin, 1982; Morris \& Peng, 1994), showed that people can identify complex psychological and social attributes from motion trajectories and geometric relationships between abstract figures. Specifically, human observers are able to elaborate inferences at three levels:

- instant causal interactions: people tend to interpret a contact between two solid objects as a transfer of energy ("red has hit blue"; "red has given a push to blue");

- extended goal-directed actions: beyond simple causal interactions, people tend to considerate larger movement patterns as indications of actions realized to complete a goal or intention ("red tries to open the door"; "blue wants to rescue orange");

- protracted narrative threads: people are able to reconstruct a narrative context to the actions they perceive, sometimes in the form of social routines or stereotypes ("red is jealous about blue and orange's relationship, he wants orange for himself and tries to force her into his lair").

This evidence from cognitive psychology, as well as the other evidence previously discussed demonstrates that human observers can produce rich behavioral interpretations from motion, in the absence of cues indicating a resemblance with a human, an animal, or even any familiar object. It also suggests that a certain empathy, a sentiment of social presence, even an emotional connection can be elicited simply by animating an object in an adequate way. However, it does not show, per se, that behavior is the most important indicator of mental states in an animated object, nor does it say anything about the relationship between the inferences derived from appearance and those derived from behavior. A form of behavioral realism seems to be sufficient for a certain social engagement to occur, but appearance establishes a frame upon which certain expectations can originate and shape the interaction (Bartneck, Kanda, Ishiguro, \& Hagita, 2007), possibly supporting or contradicting the frame delineated by behavioral properties. 
With robots, unlike with animals, behavior may dissociate from appearance. In other words, the morphology and overall appearance of a robot may trigger certain inferences that the behavior does not confirm, and vice versa. Feature traits (such as realistic face features) can activate certain assumptions about the nature of the robot and frame the expectations regarding the kind of interaction one can hope to have with it. Studies investigating the notion of anthropomorphism have shown that the simple view of a static image of a robot is enough to activate mentalistic assumptions (Kamide, Eyssel \& Arai, 2013; Rosenthal-von der Pütten \& Krämer, 2015). According to Gray \& Wegner (2012), the appearance of a humanlike robot prompts attributions of the capacity to feel and sense. This kind of assumption may conflict with the actual behavior of the robot, which is often not as sophisticated as its appearance.

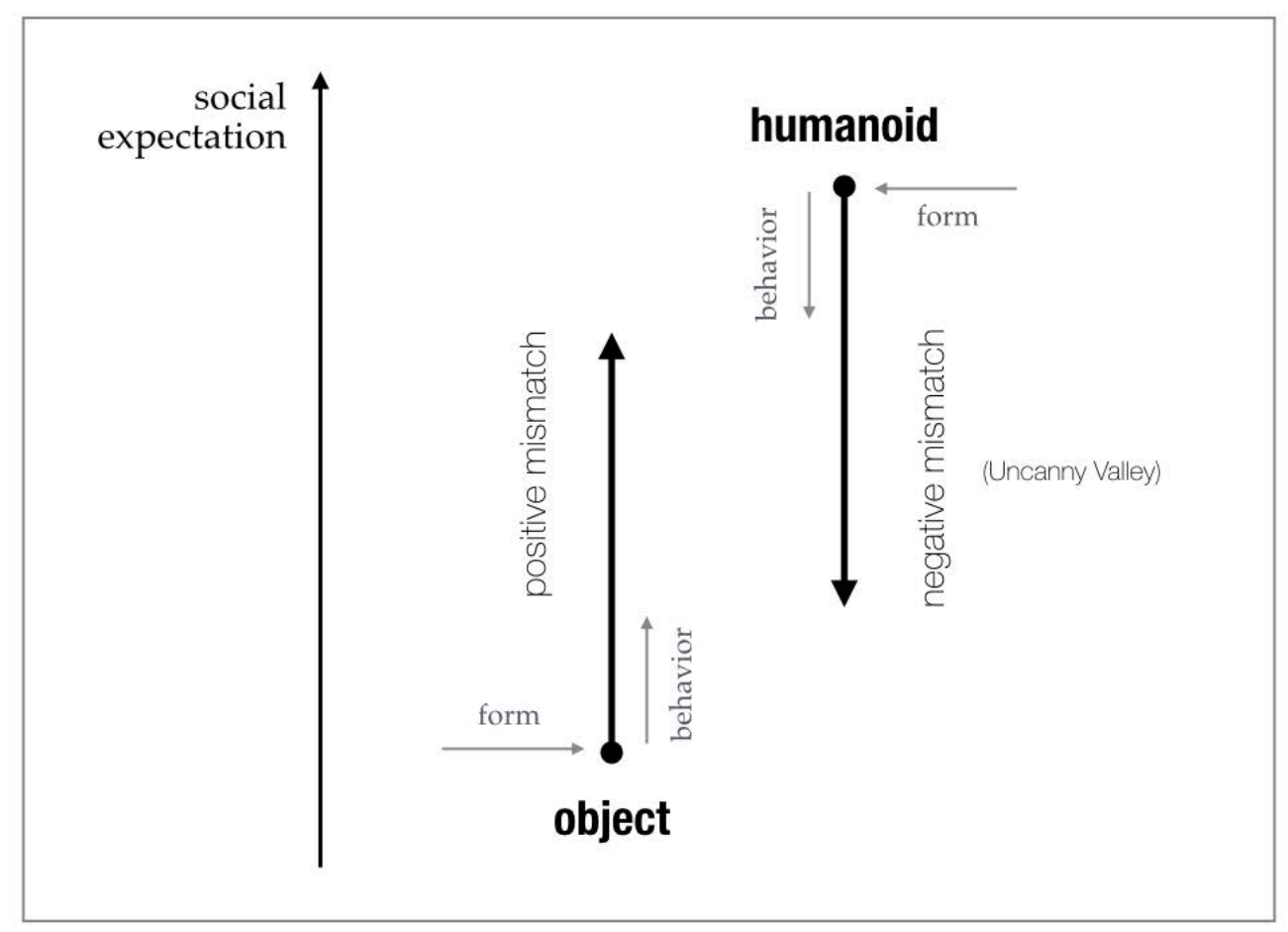

Figure 1. Relationship between form and behavior and how they affect social expectation.

The relation between form and behavioral realism, and the social status attached to a robot, can be conceived with the help of the notion of social threshold, which has been developped to account for the feeling of co-presence inside virtual environments. According to the Threshold Model of Social Influence (Blascovich, 2002; Blascovich et al., 2002; Von der Pütten, Krämer, Gratch, \& Kang, 2010), the feeling of being with one other person in a virtual environment depends both on a factor of agency (i.e., the extent to which a person knows that a virtual character is a representation of a human being) and a factor of behavioral realism. The interesting idea is that the feeling of copresence is a function of a vicarious relation between agency and behavior realism: providing one of the factors is high, co-presence may still occur even if the other factor is low. The same is probably true when confronted to a robotic artifact: A social threshold is passed when a certain level of realism has been attained, either at the morphological or behavioral level. When human resemblance is high, behavioral realism does not have to be high for a social effect to occur. Conversely, when behavioral realism is high, the artifact does not have to bear a striking or even remote resemblance to a human or an animal - this is what behavioral objects are about. A mismatch occurs when the threshold is passed but one of the factors is acting concurrently, pushing in the direction opposite to the factor that has crossed the threshold. This mismatch may be evaluated positively when an originally inert object becomes animated (think about the broom in Fantasia), it may be negative when a humanoid is acting in an odd 
fashion (e.g., think about a zombie) $)^{2}$. Fig. 1 shows this relationship between form and behavior and how they affect social expectations. The starting positions for objects and humanoids represent the impact of the form factor on social expectations - an object has no social expectations attached to it, whereas a humanoid triggers high expectations. The arrows represent the impact of the behavioral capabilities on social expectation. Adding capacities to move and express to objects allow them to enter a new range of social considerations (being perceived as companions, partners, slaves, comical sidekick, etc.). On the contrary, a humanoid with a behavior that is not consistent with what is expected from a human will risk to be degraded from its status of social agent.

\section{A Tentative Clarification of the Notions of Behavior and Behavioral Objects}

Having established that behavioral properties constitute a critical element upon which a bond between a human and a robot can develop, we would like to consider the notion of behavior itself and try to provide a more formal definition of the class of objects we are considering in this article.

On a first approximation, behavioral objects correspond to non-humanoid, non-zoomorphic artifacts that are conceived to carry out interesting and evocative behaviors. The toaster that trembles intermittently, the metallic sphere that bangs into the walls (Box 1), the table that chases people (Box 2), the camera that shies away from observers (Box 3); all these objects share a relative mundane appearance and have the property of evoking psychological traits to a human observer. With respect to the larger class of robotic artifacts, these behavioral objects occupy a position between two stereotypes that organize the fictional heritage associated to robotics: the industrial robot and the social (humanoid) robot. Contrary to the industrial robot, behavioral objects are not designed to accomplish functional tasks. As mentioned in chapter 2, their behavioral qualities constitute a supplementary layer of experience that may augment their functional value (if they have one). As seen in chapter 2, the impatient toaster vibrates in order to attract the user's attention and invite him to eat. A floppy disk drive designed by James Chamber suddenly stands up on its legs if it detects a liquid spilled nearby (Auger, 2014). The behavioral property, which consists for the disk drive to lift itself, does not constitute the functional value of the disk, but rather it augments this functional value by protecting the disk from an inadvertent coffee spill. Unlike the social robot, behavioral objects are not specifically conceived to serve, help, or cooperate with humans. Although they can sometimes mimic human social behavior (see Box 3), they are not designed to engage a user with human-like social skills, or features such as gestures, posture, body and facial traits that organize the social interaction. The point is that behavioral objects do not need these skills and features to initiate an interaction; their behavioral repertoire, which is more akin to that of an animal, is sufficient for the user to acknowledge their social presence.

Behavioral objects look to maximize the expressive potentiality of behavior by exposing it "naked," unaltered by expectations that frame the interaction when a robot resembles a human being or an animal. What then is a behavior? We speak about the behavior of a ferret, the behavior of sand, of a storm, or the behavior of stock-market prices, or of algorithms: a vast range of entities that share very few properties, not even of being of natural descent or of being material objects. Yet intuitively, the notion of behavior seems to apply more easily to organisms than to objects, more easily to dynamic entities than to inert ones, and perhaps more easily to complex things than simple ones. Behavior seems to imply the idea of some transformation (i.e., a change of state) taking place. This is not necessarily an overt transformation (for instance, a mental behavior is not something directly observable), but, to put it crudely, something happens and makes a dent in the world. We may be reluctant to qualify a rock falling from a cliff as an instance of a rock behavior: This is perhaps because the transformation (the fall) is not something that comes from the rock but rather something that happens to it, as it is embedded inside a field a forces that direct the way it evolves. The idea of being at the source, of causing the transformation, is probably an important aspect of our intuitive notion of behavior. This is not to be confused with the notion of agency, the idea that an entity acts intentionally. As such, we may evoke the behavior of a storm or the behavior of waves. While those entities are deprived of intentionality, they possess an inherent organization that subsumes the activity of a myriad of individuals or particles whose demeanor may appear at a close distance as random or unruly. Similarly, the behavior

\footnotetext{
${ }^{2}$ Note that the addition of behavioral capacities to an object will not necessarily lead to a positive mismatch. It depends if the behavior is prosocial or not. If the object proves itself aggressive, it will be considered negatively (even as frightening). Similarly, a humanoid with an odd behavior may elicit empathy (it may be perceived frail or sympathetically awkward).
} 
Levillain and Zibetti, Behavioral Objects

of a car or some other technological artifact amounts to the description of a functional organization that holds together the parts and assigns them a role inside a global machinery.

Aside from the notions of transformation and organization, behavior is also concerned with the way an organism acts and reacts to its immediate environment. We may now turn to a more formal definition of the notion of behavior inside the domain of biology to get some insight about this relationship. Authors (see Levitis, Lidicker, \& Freund, 2009) often appeal to a definition that emphasizes the relationship between a stimulation and a response from an organism. For instance: behavior is the "observable activity of an organism; anything that an organism does that involves action and/or response to stimulation" (Wallace, Sanders \& Feri, 1991). Or: behavior is the "externally visible activity of an animal, in which a coordinated pattern of sensory, motor and associated neural activity responds to changing external of internal conditions" (Beck, Liem, \& Simpson, 1991). Those definitions articulate the notion of behavior around a relationship between an organism and its environment through a neural organization that converts the excitation of sensory receptors into a motor activity. This activity is either self-generated, when not triggered by an external stimulation but from an internal signal, or a reaction to changes occurring in the environment. From this perspective, behavior is thus an ensemble of activities that are either spontaneous or caused by external variations.

Integrating these different aspects of the notion of behavior - transformation, organization, action/reaction - we are now in position to define what makes objects special, such as those we described previously. Behavioral objects produce observable transformations that are perceived as spontaneous and organized with respect to the object's environment.

1. The transformations are perceived as generated by the artifact and not the result of an external influence or the product of a mechanism;

2. Those transformations acquire a certain meaning from the context in which they occur, and especially from whether they are construed as self-generated, possibly goal-directed actions, or as reactions to some external events.

The transformation and organization we perceive and that constitute the behavior, in particular the articulation between the spontaneous activity of the object and its surrounding environment constitute the basis upon which identifying certain psychological traits, inferring intentions or emotions, and engaging into an empathic relationship.

Behavioral objects are objects that produce specific cues that, to a human brain and to the naive psychology it generates, constitute meaningful indicators of an internal state and a disposition to interact with the world. Behavioral objects are objects that we tend to anthropomorphize, in the sense that we tend to grant them qualities that we would grant to human beings. However, we want to make a distinction between those objects and regular objects like cars or computers that we also tend to anthropomorphize but do not correspond to the previous definition of behavioral objects. What does it mean to anthropomorphize a behavioral object compared to an inert object, or even a moving object, but that fails to give an impression of spontaneous activity?

\section{Anthropomorphism and the Attribution of Psychological Traits}

In our mind, the definition of behavioral objects goes beyond the mere notion of personification, the idea that lies at the root of HCI that human responses to artificial objects are fundamentally natural and social (Nass \& Moon, 2000; Reeves \& Nass, 1996). Lucy Suchman (1986 pp. 10-13) explained, for instance, that the fact to see a computer as "purposeful and, by association, as a social object" arises from the immediate reactivity of such a machine, from the fact that the means for controlling a computer are linguistic rather than mechanistic, and from the fact that the computer is essentially opaque, making the personification of the machine a good strategy to understand the way it works. We agree that the mechanism of personification, heard as a 'projection' of human attitudes or beliefs onto artificial objects, is an important component of our relation with robotic objects. However, behavioral objects are not only artificial objects impregnated with human values but embodied entities that, in a real yet very specific sense, exhibit a behavior. Behavioral objects are objects that display a sufficient range of cues to be considered by our own naive psychology as the potential recipients of mental attributes; they possess an ability to trump our sense of what is alive and what is not (Gaudiello, Lefort, \& Zibetti, 2015).

This assumption needs to receive a proper justification in the form of a disambiguation of the notion of anthropomorphism. Anthropomorphism is a widespread concept in the domain of HRI (Bartneck, Kulić, Croft, \& 
Zoghbi, 2009; Fink, 2012) but the assumptions regrouped under the concept are rarely exposed (Zawieska, Duffy, \& Strońska, 2012). In a general sense, anthropomorphism refers to the attribution of human characteristics to nonhuman entities, an object, an animal, or a natural phenomenon (Airenti, 2015; Epley, Waytz, \& Cacioppo, 2007). As put by Airenti (2015), anthropomorphism corresponds to the explanation of "nonhuman behavior as motivated by human feelings and mental states." Sketched in such general terms, the notion of anthropomorphism is at risk of lumping together two different situations and perhaps two different sets of psychological mechanisms: 1) imbuing nonhuman entities with properties and values specifically suited to the description and interpretation of human behavior; 2) inferring psychological attributes from the way a nonhuman entity moves and reacts to its environment.

On acceptation 1 (A1), anthropomorphism is a misuse, an overextension of the grasp of our mental and social concepts to entities that would be best explained using mechanistic or biologic concepts. Paradigmatic cases include, for instance, children' propensity for animism (Piaget, 1929), someone patting his computer to encourage the execution of a software, or the explanation of a natural phenomenon with the recourse of intentional entities (Barrett \& Keil, 1996; Bering, 2012). However, on acceptation 2 (A2), anthropomorphism may be a reasonable assumption, giving some perceptive evidence that an entity is able to conjure up some behavioral responses. This is what is happening when observing an animal or a robot with a sufficient autonomy ${ }^{3}$ and producing evocative motions.

On A1, anthropomorphism would arise mainly from a default of more appropriate terms, or conceptual framework, to describe what nonhuman entities are doing. For instance, according to Epley, Waytz, and Cacioppo (2007), anthropomorphism results from the immediate availability of knowledge about humans or self-knowledge for the induction of properties of nonhuman agents. This knowledge stems from the fact that humans are endowed with a social toolbox (Alexander, 1990; Humphrey, 1976) that includes the possibility of using mental states as justifications for certain observable activities (Dennett, 1989). By this account, the attribution of human characteristics to nonhumans is a natural strategy that, to some extent, allows interacting effectively with the environment, until more appropriate tools are conceptually available.

A2 corresponds to a much more circumscribed situation, its difference with A1 coming from the presence of perceptive evidence in the form of a particular behavioral organization that may constitute legitimate premises upon which psychological attributes are derived. The presence of behavioral cues triggers a form of reasoning that is akin to an abduction: a hypothesis that, if true, would best explain an observed behavior. To give an example: the psychological inference " $A$ has the intention to go to point $i$ " best explains the fact that, for instance, $A$ is going in the direction of $i$, and $A$ is persisting to go in direction of $i$ when, say, a gush of wind pushes him in another direction."

Contrary to A1 that seems to rely on an inductive process driven by general mechanisms of knowledge acquisition and activation (Epley et al., 2007; Higgins, 1996), A2 is possibly reliant on very specialized mechanisms. Some authors (Leslie, 1994; Scholl \& Gao, 2013) have argued that the mechanisms responsible for this sort of inferences based on motion are perceptive in nature, hardwired into the visual system and giving as evidence the fact that the perception of an object's motion, as caused by another object (Michotte, 1963 or by an intention to act (Heider \& Simmel, 1944), is typically fast and mandatory (i.e., you cannot help but attribute a cause to the movement). As such, the psychological inferences based on motion may be, at least partially, separated from the mentalistic concepts developed for the interaction with humans and that fuel A1 (for a similar position, see Gergely \& Csibra, 2003; Leslie, 1994).

This is not to say that the psychological attributes inferred from the observed behavior of a nonhuman necessarily correspond to real attributes. For example, pet owners frequently attribute mental and emotional traits to their pets, beyond the reach of what is available in terms of behavioral evidence. People see their dog or cat as jealous, deceitful, empathic, or manipulative. The error here may come from the attribution of specific psychological properties, but not from the general assumption that those animals possess a dog or cat equivalent of a human personality, human volition, or human decision-making ability. In fact, based on the regularities and variations observed in their pets' behavior, this is a reasonable assumption that needs to be disproved with hard facts. In this specific example, it is possible that the (justified) recognition of meaningful behavioral characteristics, and the inferences prompted by them (A2), motivates the (incorrect) attribution of human emotions and motivations (A1).

\footnotetext{
${ }^{3}$ Here we refer to the autonomy as perceived by a naive observer. The robot could be controlled at a distance and yet produce an impression of autonomy if the observer has no way of knowing that it is teleoperated.
} 
When it comes to robots, the relationship between inferred psychological attributes and real psychological properties is much more elusive. A robot's behavioral complexity depends on an algorithmic sophistication that is not necessarily modeled on natural cognitive abilities. Robots do not need to possess the endogenous organization that, in humans and complex animals, is responsible for their behavior; what they need is to simulate the external manifestation of such an organization (Braitenberg, 1981; Brooks, 1991; Langton, 1989). Robots can have an anthropomorphic aspect, and thus invite the kind of intuitions that we refer to as A1. But, as we have seen in chapter 3 , the psychological attribution process that we refer to as A2 is not dependent on how similar the robot is to a living being. Behavioral objects can be very dissimilar to a human or an animal, yet, because of the transformations they produce, trigger the same kind of attributions that would be activated by the motion of a living being. To stress the point, behavioral objects distinguish themselves from other mechanical artifacts by the fact that they provide evidence upon which human-naive psychology can elaborate inferences relative to the source and the justification of the observed behavior. These inferences are the subject of the next chapter.

\section{A Cognitive Framework for the Design of Behavioral Objects}

One could dismiss the notion of behavioral qualities on the ground that the appreciation of such qualities is inherently subjective. We were motivated to produce this article to demonstrate that behavioral qualities can be made more tangible providing an adequate framework that envisions the perception of spontaneous transformations in light of the cues they manifest about the underlying psychological dispositions of an animated entity. The intuitions we referred to as $\mathrm{A} 2$ in the previous chapter have a justification in that they reflect the cognitive mechanisms that evolved to produce a coherent picture of the behavior of animated beings. The following framework is a tentative review of the existing literature on the perception of animacy and agency. More than a proposition about the organization of the cognitive mechanisms involved, its aim is to present in a systematic fashion the motion patterns that have been identified as especially important for action understanding. This framework is basically concerned with the emergence of a perceived intentionality in a robot's behavior and does not address the affective qualities expressed by motion features ${ }^{4}$.

The ability to interpret the movements of objects in terms of behavior, action, intention, or personality traits forms the basis of research on action understanding (Baldwin \& Baird, 2001; Levillain \& Zibetti, 2012; Zacks, Speer, Swallow, Braver, \& Reynolds, 2007), and particularly, studies focusing on perception of animacy and agency (Leslie, 1988; Michotte, 1963; Premack, 1990; Scholl \& Tremoulet, 2000). What is unique about these studies is that movement is considered as an intrinsic source of information about the causal or intentional origins of behavior (e.g., Choi \& Scholl, 2004; Csibra, 2008). The human perceptual system's ability to identify psychological attributes on the sole basis of movement is particularly useful to the production of artifacts, which due to their very nature are different from natural biological forms. This means that in spite of very little morphological similarity, it is possible to sustain rich psychological attributions by animating these artifacts in an appropriate way.

Is it possible to use the behavioral information embedded in these objects to systematically characterize the attitudes and psychological properties that will be suggested to the observer? The approach used by Braitenberg (1981) for a theoretical machine would be ideally suited to achieving this goal. This approach would involve incrementally increasing the number of actions a machine with very rudimentary behavioral abilities is capable of, by progressively adding perceptual discrimination abilities, a memory, a value system to sustain exploratory behavior, schemas to enable recognition of actions by similar objects, and social communication abilities; the approach would involve examining, at each stage, the machine's behavioral cues and how these cues were interpreted. This type of systematic study does not exist, but the literature includes numerous examples of behavioral cues that appear to play a crucial role in triggering certain psychological attributions.

In the framework we propose, these behavioral cues are categorized according to three levels of interpretation: the Animacy level, the Agency level, and the Mental Agency level (Fig. 2). In essence, the three levels correspond to the three following questions: Does the object look alive? Does the object appear to act intentionally? Does the object appear to take into account others' goals?

\footnotetext{
${ }^{4}$ We refer the reader to De Rooij, Broekens, \& Lamers (2013) for a review of the affective qualities evoked by kinematic features (see also Kleinsmith \& Bianchi-Bethouze, 2013).
} 
At the Animacy level, a moving object is perceived as basically autonomous: it seems to move on its own and may give the impression of reacting to its immediate environment. While the object may initiate an interaction with its surroundings through movements of attraction or repulsion, its behavior is still too erratic to be qualified as fully intentional.

At the Agency level, the behavior of a moving object is construed as goal-oriented: the object seems to act for the realization of specific actions and to organize its behavior flexibly and rationally to reach those ends.

At the Mental Agency level, a moving object already identified as intentional is also granted the ability to represent the content of others' mind. This means that the agent's behavior is perceived as not only related to the properties of the immediate environment, but also to the behavior of other agents with whom it may try to interact and communicate.

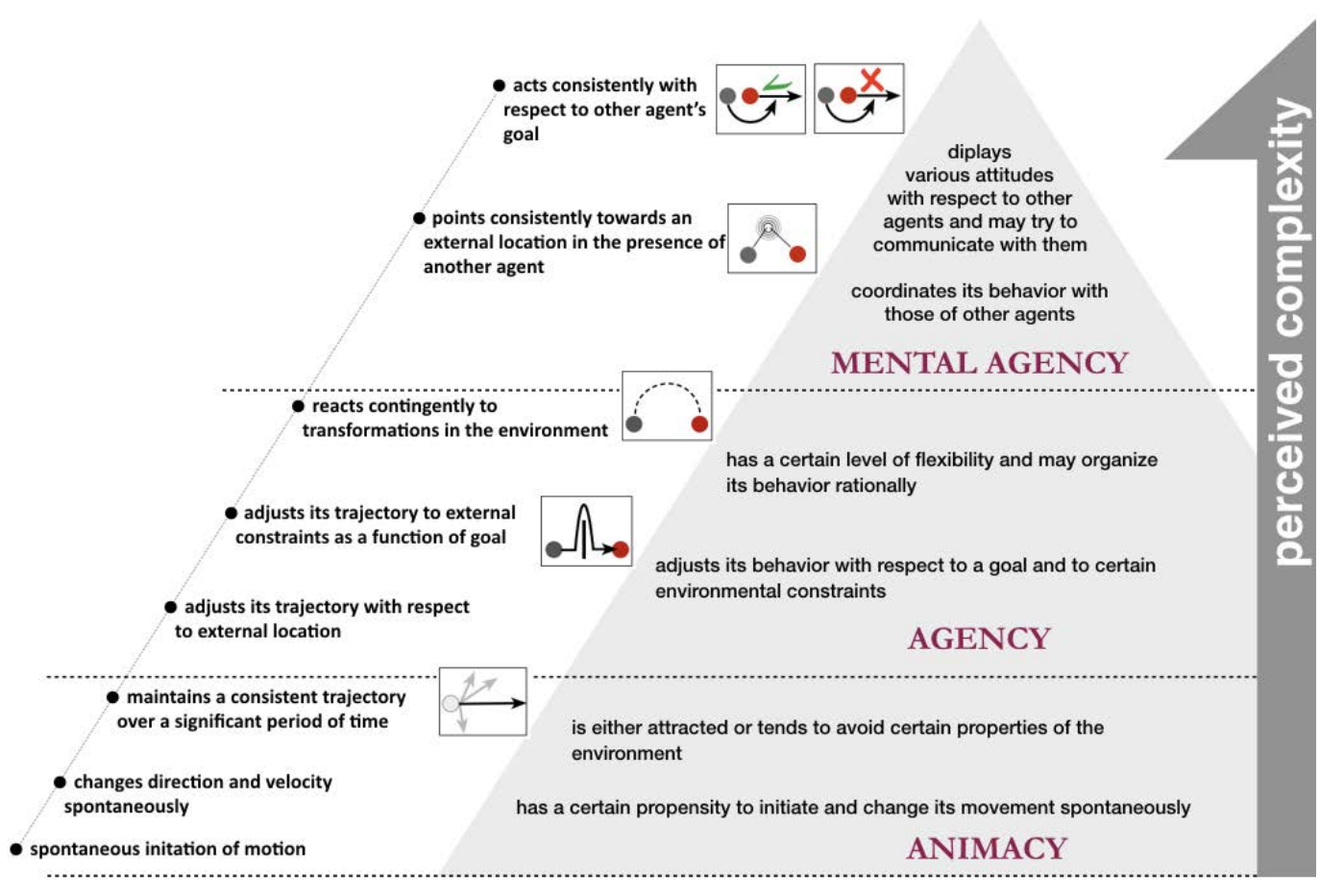

Figure 2. Animacy, Agency, Mental Agency: Three levels of interpretation to characterize the spontaneous attribution of psychological traits from motion. Different behavioral markers corresponding to motion cues and motion patterns that an object may produce are represented to the left of the triangle. Inside the triangle, are the inferences produced by an observer in reaction to the potentially perceived behavioral markers.

Fig. 2 represents an attempt to categorize both of the movement cues a behavioral artifact can demonstrate and inferences made by the observer. Increased behavioral complexity corresponds to a diversification of the movement cues that can be observed and also to an increasing richness of inferences. For example, if we suppose that an object is able to pursue goals, we can consider not only the immediate causes of its behavior (e.g., if it collides with something) but also causes that are not directly observable, such as the determination to reach a particular destination, that we attribute to the object. Providing a description of a behavioral artifact requires us to consider aspects related to its autonomy and, as a result, the complete, intentional character of the actions it produces.

We hypothesize that movement from one level of interpretation to another occurs when certain behavioral "markers" are observed. These markers are particular critical cues, operating at the level of the way the object moves, which will compel observers to readjust the psychological properties that they attribute to the object. First, 
objects situated at the Animacy level have a propensity to initiate and change the direction and speed of their movements spontaneously. The fact that the object can initiate movement spontaneously forces the observer to consider that it is possible for the object to manage its movement independently of external energy sources, and thus be subjected to causal forces other than mechanical physics. Simple motion cues relative to the spontaneous production of movement have a strong impact on the naive perception of animacy (Lepage, \& Ferland, 1996; Markson \& Spelke, 2006; Poulin-Dubois, Premack, 1990). Seeing a simple dot on a screen changing direction suddenly is often enough to give the illusion of a living being, although the strength of the impressions depend largely on the importance of the direction change and possibly of the speed change (Trauble, Pauen, \& PoulinDubois, 2014; Tremoulet \& Feldman, 2000).

The transition from the impression of an autonomous yet erratic entity to the impression of a goal-oriented entity will depend on the consistency of the behavior over time: If the objects maintains consistent trajectories rather than changing direction at every turn, we are likely to infer in it the ability to maintain consistent objectives (Gao, Newman, \& Scholl, 2009; Gao \& Scholl, 2011). This impression will be reinforced by the possibility of connecting the object's movement to a specific location toward which it appears to be moving (Gelman \& Gottfried, 1996; Montgomery \& Montgomery, 2010; Tremoulet \& Feldman, 2006). Compared to the Animacy level, entities at the Agency level have a flexibility in their behavior; they act purposefully and may organize their actions in a rational manner so as to reach a goal in the most efficient way. Seeing a moving object adjusting its behavior with respect to external constraints is a potent indication that it does indeed possess the ability to select appropriate means to achieve a goal (Csibra \& Gergely, 1998; Király, Jovanovic, Prinz, Aschersleben, \& Gergely, 2003). Thus, if an agent's goal is to reach another object and there is no obstacle in its way, it would seem more reasonable for the first object to move in a straight line rather than jump around (Gergely, Nádasdy, Csibra, \& Bíró, 1995). In the observer's opinion, an object's behavior appears all the more intentional if it conforms to this rationality principle.

The Agency level probably corresponds to the level of behavioral organization suited for anthropomorphic properties to start being attributed to a robot. It is the level at which the observed behavior is sufficiently consistent for adjectives relative to the internal experience to be attributed. Below that level, the behavior of a moving entity may be considered too erratic to receive qualifications that entail more than a fugitive impression of sentience. A Roomba would qualify for the Agency level, in as much as its behavior is sufficiently thorough for people to start attributing it qualities germane to the planification of action over a certain period of time, such as a relative intelligence and the will to do a good job (Forlizzi \& DiSalvo, 2006; Sung, Guo, Grinter, \& Christensen, 2007). We can speculate that the sentiment of being in presence with another being, which initially depends on the perception of spontaneous movements (Animacy level), lays the groundwork for a more intricate relationship based on the attribution of psychological characteristics (Agency level). This relationship is bound to develop as new evidence is given to the observer that the object is capable of adapting its behavior to the environment, as well as to other agents.

Moving from the Agency level to the Mental Agency level occurs through the observation of ways in which two objects adjust their behavior in relation to one another (Bassili, 1976). The simplest example of social interaction is when one agent is followed by another (Dittrich \& Lea, 1994; Gao et al., 2009; Gao \& Scholl, 2011; Opfer, 2002). The object following constantly adjusts its direction according to where the object in front is going, through a series of contingent interactions. This shows that the object is able to evaluate certain behavioral cues coming from the other object and to estimate its future direction. These types of short-term adjustments can also provide information about the object's ability to engage in joint attention, or to establish a joint attentional space (Tomasello, 1995), in which a basic form of communication can be organized, in particular through the use of deictic gestures (Kendon, 2004).

At a higher level of complexity, agents are perceived as possessing the capacity to act not only relative to their own goals but also relative to other agents' goals. This ability is often framed in terms of a theory of mind that individuals possess and that allow them to attribute mental states to others (see Goldman, 2012, for a review of this concept). In this framework, reaching the level of Mental Agency means that an observer has the impression that the robotic artifact coordinates its own actions with those of another agent in its environment. This perceived coordination constitutes, in turn, a possible indication that the robotic artifact possesses an ability to infer certain mental dispositions in another agent. This property of mind reading will be purely illusory, as no robots is actually capable of such a cognitive feat, but the impression may nevertheless prove enduring if certain 'tricks' are 
implemented that allow the robot to consider certain properties of an agent's action planification to organize its own behavior.

At the Mental Agency level, it is possible to ascertain prosocial or antisocial attitudes on the part of the agents. For example, studies by Hamlin and colleagues (Hamlin \& Wynn, 2011; Hamlin, Wynn, \& Bloom, 2007) demonstrated that very young children are sensitive to the altruistic nature of an action when presented only with an animation showing two schematic objects. The children tended to prefer the object that had previously been shown to "help" another object to go up a slope by pushing it, rather than the object that was shown to "hinder" the other object from going up the slope by placing itself in front of it. In this case, the determination of social attitudes comes about through a mechanism which assesses whether goals are convergent (for a positive attitude) or divergent (for a negative attitude).

Depending on the cues offered by the object's behavior, and the level at which that behavior is construed, certain personality traits may be spontaneously attributed to the object. A robotic artifact may look curious, mischievous, indifferent... based on the way it organizes its movements, reacts to external events, or interacts with other agents (Van den Brule, Dotsch, Bijlstra, Wigboldus, \& Haselager, 2014). An object seen merely as autonomous (Animacy level) may not be granted any proper personality traits, its behavior simply not being organized enough to be qualified with a psychological attribute. However, as soon as the object's behavior can be related to intentions (Agency level), a vast range of psychological dimensions are available to qualify it, for instance how effective the agent is in the accomplishment of an action, how rational, how persistent, how thorough it is in the exploration of its environment, etc. At the Mental Agency level, even more psychological components can be used to qualify the agent's behavior, based on, for instance, the proficiency with which it interacts socially, its propensity to engage in communication behaviors, or its tendency to pursue positively or negatively valued behaviors (Van den Brule et al., 2014).

The motion patterns that we described have been deliberately abstracted from the appearance of the object that enacts them. In fact, it is possible to conceive a minimally complex shape, such as a dot, that would carry out these different behaviors. However, this is a simplification of the complex web of inferences that is taking place when interpreting a behavior. In particular, as mentioned in chapter 3, an object's appearance carries its own frame of expectation that may influence the status and behavioral capabilities attributed to a robotic artifact. The frame of expectation delineated by the form factor and the frame drawn by the behavioral factor may interact or contribute vicariously to the construction of a mental map of the object's behavioral organization. These two frames of expectation may come to contradict one another. Let's take an example: The Insecurity Camera (see Box 3) reaches the Mental Agency level by implementing social contingencies (the camera turns away each time it detects a person in its field). These social contingencies prompt the observer to locate the camera's motivations inside a psychological frame: The camera is perceived as shy, not "wanting" to be looked at in the eyes. In turn, a mismatch appears between the expectations associated to the security camera as a category of objects with a specific function (it is supposed to watch you) and its actual behavior (it avoids your gaze). This contradiction adds to the artwork an element of surprise and humor that bears a relationship to the artist's intention to comment on a mundane object and its usage. We can see here that the relationship to a behavioral object is mediated both by the hardwired capacities to detect an ensemble of behavioral and social cues and by the previous knowledge associated to the object that is presented in a new guise. This interplay participates to the dynamic construction of the status granted to the object, as an animated entity and a bearer of the designer's intent to distort a common usage.

As we have seen in chapter 3, a robotic artifact's social presence is achieved either through its form realism (a humanoid appearance) or through its behavioral realism. The framework we proposed may make it more substantive this notion of behavioral realism: A behavior is realistic when it possesses a certain amount of the motion characteristics we described and leads to the attribution of psychological traits. However, social presence should not be considered as something clearly defined. Depending on the richness and complexity of the inferences triggered by motion patterns, social presence may have a variety of manifestations and can be broken down into different degrees between an altogether absence of presence to a full-fledged human social presence. Contemporary art installations involving behavioral objects often play with spectators' expectations, staging objects with an uncertainty surrounding their status, suspended between animate and inanimate, artificial and alive (Bianchini \& Quinz, 2016). This uncertainty regarding the ontological status reflects an oscillating social presence that may result from insufficient or ambiguous cues available to the observer to conclude to a genuine agency on the part of the robotic artifact (Levillain et al., 2016). This uncertainty is common to the class of robots. 
Contrary to living beings, robots are not perceived as having an essence (Sloman \& Malt, 2003); they are a composite set of elements that are continuously replaced and renewed. Robots, as proposed by a certain number of authors (Kahn et al., 2012; Severson \& Carlson, 2010), could be the expression of a new ontological category, neither alive nor not alive, something altogether different, something belonging to personified or behavioral technologies. While people are often reluctant to attribute them the capacity of free will, including the possibility to make voluntary choices (Monroe, Dillon \& Malle, 2014; Montague, 2008), they simultaneously grant them certain cognitive and emotional states. Robots lack a soul and yet are being endowed with capacities of action, decisionmaking, or social interaction. Is this ontological ambiguity bound to persist as robots become more sophisticated and become more pervasive in our environment? To develop a rich relationship with humans, a relationship of continuously renewed interest, robots have to get past stereotypic behaviors that are at risk of looking increasingly dull as users become accustomed to them. Robots ought to be endowed with a certain amount of plasticity, with the opportunity to surprise the user by showing unanticipated behaviors. Such a behavioral plasticity certainly depends on the development of artificial intelligence, but there is a path to complexity that does not rely on the intrinsic intelligence of the animated device but rather on the possibility for patterns and properties to emerge as the result of a complex web of interdependent variables and feedback loops. The moving pianos we presented at the beginning of this article constitute an example of emergent behavior, a constantly evolving and unpredictable arrangement that results from the pianos' motion directives, the stochastic noise introduced in their movement, the installation layout, the random encounters between the pianos, and with the visitors that evolve freely inside the installation.

Finally, the emergent behavior of behavioral objects would also depend on the material these objects are made of. What if the pianos, instead of being rigid objects, were made of a material sensitive to the environment? Smart materials such as shape-memory polymers or magnetostrictive materials, with properties controllable by external stimuli, are introducing an additional layer of complexity to robotic devices, and another layer of interpretation for the observer to derive psychological properties. The road to behavioral complexity can therefore be reached with a certain economy of means in terms of the computational sophistication of the robotic artifact, but the comprehension of the emergent behavioral properties ought to be supported by the development of theories to elucidate how motion transforms into some psychological attributions.

\section{Conclusion}

In this article, we have explored the consequences of granting objects behavioral properties. Those behavioral properties force to reconsider, even redefine, the relationship between form and function that normally informs design practice: The psychological qualities that may arise from observing the behavior of an artifact introduce a supplementary layer of interpretation and an access to new types of emotional relationships and interactions. Those qualities stem from a hardwired tendency of the human brain to consider movement traces as potential indicators of inner states and personality traits.

As we have seen, the relationship to these behavioral artifacts should not be conceived from a strict anthropomorphic point of view, heard as the interpretation of a non-human behavior in terms of human mental concepts. Anthropomorphism is a multi-layered phenomenon (Persson, Laaksolahti, \& Lönnqvist, 2000; Ruijten, Bouten, Rouschop, Ham, \& Midden, 2014) that encompasses different levels of categorization and cognitive attribution. What we have suggested is that there is a level of interpretation of the behavior that may occur prior to the attribution of mentalistic concepts, which qualifies the organizational complexity of the observed behavior (Levillain \& Zibetti, 2012) and determines a type of intuitive relation to behavioral artifacts.

From the fact that an intuitive connection to behavioral objects arises from simple patterns of movements, it is possible to overcome the usual difficulty in social robotics of trying to establish a rich and significant dynamic between humans and robots by focusing on making robots' behavior evocative rather than on putting an emphasis on morphological realism. As seen within contemporary art, the creation of situations involving partially autonomous objects can lead to suggestions of more complex interactions and can also enable the type of relationships underlying these interactions to be determined (Levillain et al., 2016).

This move away from the aesthetics of form to a focus on movement and emotions within the context of interaction might provide a response to particular debates within HRI design and a way of moving toward greater social acceptance of robotized objects. It is important to allow unexpected interpretations and interactions to emerge 
and to leave space for individuals to be surprised by behaviors they had not anticipated (Duffy, 2003). Surprise and ambiguity can be helpful properties, not only in art but also in industrial design and social robotics, because they can, for example, help users to rethink the role played by an object in their lives and, more generally, to reconsider their relationship with technology (Hassenzahl, 2010, Khan, 2009). In this sense, ambiguity opens up a space for interpretation (Sengers \& Gaver, 2006), and it may encourage a more personal engagement with behavioral artifacts (Gaver, Beaver, \& Benford, 2003; Salem, Eyssel, Rohlfing, Kopp, \& Joublin, 2013; Salem, Lakatos, \& Amirabdollahian, 2015). The role of the behavioral artifact designer is to determine the level of interpretation required for a user to understand an object. Variables such as how active and autonomous an object is perceived, and how it is trusted to be able to make decisions (Gaudiello, Zibetti, Lefort ${ }_{2} \&$ Chetouani, 2016), will create an illusion of a living, conscious presence and will have a vital impact on the relationship that the user is prepared to have with the object (Salem et al., 2015). Being able to engage the user in interpreting artifacts' behavior, in terms of emotional states and personality traits, undoubtedly represents one of the biggest challenges in HRI, but it also represents a way of exploring and channeling human beings' natural tendency for empathy.

\section{Acknowledgments}

This research was developed as part of a collaboration with the ENSADLAB Reflective Interaction team (directed by Samuel Bianchini), The Centre Georges Pompidou and the University Paris 8, inside the "Behaviors of Things" research program (Program Manager Emanuele Quinz) supported, through the Labex Arts-H2H, by Investissements d'Avenir (ANR-10-LABX-80-01) of the French National Research Agency (ANR). We are especially grateful to Emanuele Quinz and Samuel Bianchini for introducing us to the domain of behavioral artworks in contemporary art and for giving us the opportunity to develop the framework proposed in this article.

\section{References}

Airenti, G. (2015). The cognitive bases of anthropomorphism: From relatedness to empathy. International Journal of Social Robotics, 7(1), 117-127. doi:10.1007/s12369-014-0263-X

Auger, J. H. (2014). Living with robots: A speculative design approach. Journal of Human-Robot Interaction, 3(1), 20-42. doi:10.5898/JHRI.3.1.Auger

Alexander, R. D. (1990). How did humans evolve? Reflections on the uniquely unique species. Museum of Zoology (Special Publication $\mathrm{N}^{\circ} 1$ ). Ann Arbor, MI: The University of Michigan.

Bailenson, J. N., Yee, N., \& Merget, D. (2006). The effect of behavioral realism and form realism of real-time avatar faces on verbal disclosure, nonverbal disclosure, emotion recognition, and copresence in dyadic interaction. Presence: Teleoperators and Virtual Environments, 15(4), 359-372. doi:10.1162/pres.15.4.359

Baldwin, D., \& Baird, J. (2001). Discerning intentions in dynamic human action. Trends in Cognitive Sciences, 5(4), 171-178. doi:10.1016/s1364-6613(00)01615-6

Barrett, J. L., \& Keil, F. C. (1996). Conceptualizing a nonnatural entity: Anthropomorphism in God concepts. Cognitive Psychology, 31(3), 219-247. doi:10.1006/cogp.1996.0017

Bartneck, C., Kanda, T., Ishiguro, H., Hagita, N. (2007) Is the uncanny valley an uncanny cliff? In Proceedings of the 16th IEEE International Conference on Robot \& Human Interactive Communication. pp 368-373. Piscataway, NJ: IEEE. doi:10.1109/ROMAN.2007.4415111

Bartneck, C., Kulić, D., Croft, E., \& Zoghbi, S. (2009). Measurement instruments for the anthropomorphism, animacy, likeability, perceived intelligence, and perceived safety of robots. International Journal of Social Robotics, 1(1), 71-81. doi:10.1007/s12369-008-0001-3

Bassili, J. N. (1976). Temporal and spatial contingencies in the perception of social events. Journal of Personality and Social Psychology, 33(6), 680-685. doi:10.1037/0022-3514.33.6.680

Beck, A., Liem, K. F., \& Simpson, G. G. (1991). Life, an introduction to biology. New York: Harper Collins.

Bering, J. (2012). The belief instinct: The psychology of souls, destiny, and the meaning of life. New York: WW Norton \& Company. 
Levillain and Zibetti, Behavioral Objects

Bianchini, S., \& Quinz, E. (2016). Behavioral Objects 1. A case study: Céleste Boursier-Mougenot. Berlin: Sternberg Press.

Bianchini, S., Bourganel, R., Quinz, E., Levillain, F., \& Zibetti, E. (2015). (Mis)Behavioral objects. Empowerment of users vs. empowerment of objects. Empowering Users through Design, 129-152. New York: Springer.

Bilda, Z., Candy, L., \& Edmonds, E. (2008). Designing for creative engagement. Design Studies, 29(6), 525-540. doi:10.1016/j.destud.2008.07.009

Biocca, F., Harms, C., \& Burgoon, J. K. (2003). Toward a more robust theory and measure of social presence: Review and suggested criteria. Presence: Teleoperators and Virtual Environments, 12(5), 456-480. doi:10.1162/105474603322761270

Blascovich, J. (2002). A theoretical model of social influence for increasing the utility of collaborative virtual environments (pp. 25-30). Presented at the 4th International Conference on Collaborative Virtual Environments, Bonn, Germany: ACM. doi:10.1145/571878.571883

Blascovich, J., Loomis, J., Beall, A. C., Swinth, K. R., Hoyt, C. L., \& Bailenson, J. N. (2002). Immersive virtual environment technology as a methodological tool for social psychology. Psychological Inquiry, 13(2), 103124. doi:10.1207/S15327965PLI1302_01

Boehner, K., DePaula, R., Dourish, P., \& Sengers, P. (2007). How emotion is made and measured. International Journal of Human-Computer Studies, 65(4), 275-291. doi:10.1016/j.ijhcs.2006.11.016

Braitenberg, V. (1981). Vehicles: Experiments in synthetic psychology. MA: MIT Press.

Brooks, R.A. (1991). Intelligence without representation. Artificial Intelligence, 47, 139-60.

Brown, E., Rodenberg, N., Amend, J., Mozeika, A., Steltz, E., Zakin, M. R., Lipson, H., Jaeger, H. M. (2010). Universal robotic gripper based on the jamming of granular material. In Proceedings of the National Academy of Sciences of the United States of America, 107(44), 18809-18814. doi:10.1073/pnas.1003250107

Burneleit, E., Hemmert, F., \& Wettach, R. (2009). Living interfaces: The impatient toaster. In Proceedings of the $3 r$ International Conference on Tangible and Embedded Interaction (TEI), 21-22. Cambridge, UK.

Castelli, F., Happé, F., Frith, U., \& Frith, C. (2000). Movement and mind: A functional imaging study of perception and interpretation of complex intentional movement patterns. Neurolmage, 12(3), 314-325. doi:10.1006/nimg.2000.0612

Choi, H., \& Scholl, B. J. (2004). Effects of grouping and attention on the perception of causality. Perception and Psychophysics, 66(6), 926-942.

Csibra, G. (2008). Goal attribution to inanimate agents by 6.5-month-old infants. Cognition, 107(2), 705-717. doi:10.1016/j.cognition.2007.08.001

Csibra, G., \& Gergely, G. (1998). The teleological origins of mentalistic action explanations: A developmental hypothesis. Developmental Science, 1(2), 255-259. doi:10.1111/1467-7687.00039

Damiano, L., Dumouchel, P., \& Lehmann, H. (2014). Towards human-robot affective co-evolution overcoming oppositions in constructing emotions and empathy. International Journal of Social Robotics, 7(1), 7-18. doi:10.1007/s12369-014-0258-7

De Rooij, A., Broekens, J., \& Lamers, M. H. (2013). Abstract expressions of affect. International Journal of Synthetic Emotions, 4(1), 1-31. doi:10.4018/jse.2013010101

Demirbilek, O., \& Sener, B. (2003). Product design, semantics and emotional response. Ergonomics, 46(13), 13461360. doi:10.1080/00140130310001610874

Dennett, D. C. (1989). The intentional stance. Cambridge, MA: MIT Press.

Desmet, P. (2003a). A multilayered model of product emotions. The Design Journal, 6(2), 4-13. doi:10.2752/146069203789355480 
Desmet, P. (2003b). From disgust to desire: How products elicit emotions. In: D. McDonagh, P. Hekkert, J. van Erp, \& D. Gyi (Eds.). Design and emotion: The experience of everyday things. New York: Taylor \& Francis.

Dunne, A., \& Raby, F. (2007). Critical Design FAQ. Retrieved from http://www.dunneandraby.co.uk/content/bydandr/13/0

Dunne, A., \& Raby, F. (2001). Design noir: The secret life of electronic objects. New York: Princeton Architectural Press.

Dittrich, W. H., \& Lea, S. E. G. (1994). Visual perception of intentional motion. Perception, 23(3), 253-268. doi:10.1068/p230253

Djajadiningrat, T., Wensveen, S., Frens, J., \& Overbeeke, K. (2004). Tangible products: redressing the balance between appearance and action. Personal and Ubiquitous Computing, 8(5), 294-309.

Duffy, B. R. (2003). Anthropomorphism and the social robot. Robotics and Autonomous Systems, 42(3), 177-190. doi:10.1016/s0921-8890(02)00374-3

Epley, N., Waytz, A., \& Cacioppo, J. T. (2007). On seeing human: A three-factor theory of anthropomorphism., 114(4), 864-886. doi:10.1037/0033-295X.114.4.864

Fink, J. (2012). Anthropomorphism and Human Likeness in the Design of Robots and Human-Robot Interaction. Social Robotics, 7621, 199-208. doi:10.1007/978-3-642-34103-8_20

Forlizzi, J. (2007). How robotic products become social products: An ethnographic study of cleaning in the home. In Proceedings of the 2nd ACM/IEEE International Conference on Human-Robot Interaction, 129-136.

Forlizzi, J., \& DiSalvo, C. (2006). Service robots in the domestic environment: A study of the Roomba vaccum in the home. In Proceedings of the 1st ACM SIGCHI/SIGART Conference on Human-Robot Interaction, 58-56.

Gao, T., Newman, G. E., \& Scholl, B. J. (2009). The psychophysics of chasing: A case study in the perception of animacy. Cognitive Psychology, 59(2), 154-179. doi:10.1016/j.cogpsych.2009.03.001

Gao, T., \& Scholl, B. J. (2011). Chasing vs. stalking: Interrupting the perception of animacy. Journal of Experimental Psychology: Human Perception and Performance, 37(3), 669-684. doi:10.1037/a0020735

Garau, M. (2003). The impact of avatar fidelity on social interaction in virtual environments. (Ph.D. thesis). Department of Computer Science, University College London.

Gaudiello, I., Lefort, S., \& Zibetti, E. (2015). The ontological and functional status of robots: How firm our representations are? Computers in Human Behavior, 50, 259-273. doi:10.1016/j.chb.2015.03.060

Gaudiello, I., Zibetti E., Lefort, S., Chetouani, M., Ivaldi S. (2016). Trust as a common indicator of functional and social acceptance. An experimental study on users' conformation to iCub opinion. Computer in Human Behavior, 61, 633-655. doi:10.1016/j.chb.2016.03.057

Gaver, W. W., Beaver, J., \& Benford, S. (2003). Ambiguity as a resource for design. In Proceedings of the SIGCHI Conference on Human Factors in Computing Systems (CHI), 233-240. doi:10.1145/642611.642653

Gelman, S. A., \& Gottfried, G. M. (1996). Children's causal explanations of animate and inanimate motion. Child Development, 67(5), 1970. doi:10.2307/1131604

Gergely, G., \& Csibra, G. (2003). Teleological reasoning in infancy: The naïve theory of rational action. Trends in Cognitive Sciences, 7(7), 287-292. doi:10.1016/S1364-6613(03)00128-1

Gergely, G., Nádasdy, Z., Csibra, G., \& Bíró, S. (1995). Taking the intentional stance at 12 months of age. Cognition, 56(2), 165-193.

Gibson, J. J. (1979). The ecological approach to visual perception. Psychology Press.

Goetz, J., Kiesler, S., \& Powers, A. (2003). Matching robot appearance and behavior to tasks to improve humanrobot cooperation. In Proceedings of Robot and Human Interactive Communication (ROMAN), 12th IEEE International Workshop, 55-60. Millbrae, CA.

Goldman, A. I. (2012). Theory of mind. In E. Margolis, \& S. P. Stich (Eds.). The Oxford Handbook of Philosophy of Cognitive Science, 402-424. London: Oxford University Press. 
Levillain and Zibetti, Behavioral Objects

Gray, K., \& Wegner, D. M. (2012). Feeling robots and human zombies: Mind perception and the uncanny valley. Cognition, 125(1), 125-130. doi:10.1016/j.cognition.2012.06.007

Hamlin, J. K., \& Wynn, K. (2011). Young infants prefer prosocial to antisocial others. Cognitive Development, 26(1), 30-39. doi:10.1016/j.cogdev.2010.09.001

Hamlin, J. K., Wynn, K., \& Bloom, P. (2007). Social evaluation by preverbal infants. Nature, 450(7169), 557-559. doi:10.1038/nature06288

Hassenzahl, M. (2010). Experience design: Technology for all the right reasons. San Rafael, CA: Morgan \& Claypool.

Heider, F., \& Simmel, M. (1944). An experimental study of apparent behavior. The American Journal of Psychology, 57(2), 243. doi:10.2307/1416950

Higgins, E. T. (1996). Knowledge activation: Accessibility, applicability, and salience. In E. T. Higgins, \& A. W. Kruglanski (Eds.). Social psychology handbook of basic principles, 133-168. New York: Guildford Press.

Hoffman, G., \& Ju, W. (2014). Designing robots with movement in mind. Journal of Human-Robot Interaction, 3(1), 89-122. doi:10.5898/JHRI.3.1.Hoffman

Hummels, C., Overbeeke, K. C., \& Klooster, S. (2007). Move to get moved: a search for methods, tools and knowledge to design for expressive and rich movement-based interaction. Personal and Ubiquitous Computing, 11(8), 677-690.

Humphrey, N. K. (1976). The social function of intellect. In P. P. G. Bateson, \& R. A. Hinde (Eds.). Growing points in ethology, 303-317. MA: Cambridge University Press.

Joosse, M., Sardar, A., Lohse, M., \& Evers, V. (2013). BEHAVE-II : The revised set of measures to assess users' attitudinal and behavioral responses to a social robot. International Journal of Social Robotics, 5(3), 379388. doi:10.1007/s12369-013-0191-1

Ju, W., \& Takayama, L. (2009). Approachability: How people interpret automatic door movement as gesture. International Journal of Design, 3(2), 1-10.

Kahn, P. H., Kanda, T., Ishiguro, H., Freier, N. G., Severson, R. L., Gill, B. T., Ruckert, J. H., \& Shen, S. (2012). "Robovie, you'll have to go into the closet now": Children's social and moral relationships with a humanoid robot. Developmental Psychology, 48(2), 303-314. doi:10.1037/a0027033

Kassin, K. (1982). Heider and Simmel revisited: Causal attribution and the animated film technique. Review of Personality and Social Psychology, 3, 145-169.

Kendon, A. (2004). Gesture: Visible action as utterance. MA: Cambridge University Press.

Khalid, H. M. (2006). Embracing diversity in user needs for affective design. Applied Ergonomics, 37(4), 409-418. doi:10.1016/j.apergo.2006.04.005

Király, I., Jovanovic, B., Prinz, W., Aschersleben, G., \& Gergely, G. (2003). The early origins of goal attribution in infancy. Consciousness and Cognition, 12(4), 752-769. doi:10.1016/S1053-8100(03)00084-9

Kleinsmith, A., \& Bianchi-Berthouze, N. (2013). Affective body expression perception and recognition: A survey. IEEE Transactions on Affective Computing, 4(1), 15-33. doi:10.1109/t-affc.2012.16

Langton, C.G. (Ed.) (1989). Artificial life: The proceedings of an interdisciplinary workshop on the synthesis and simulation of living systems, held September 1987 in Los Alamos, New Mexico. pp. 1-47. Redwood City CA: Addison-Wesley.

Laschke, M., Hassenzahl, M., \& Diefenbach, S. (2012). Things with attitude: Transformational products. Createl1 Conference, 1-2.

Leslie, A. M. (1988). The Necessity of illusion: Perception and thought in infancy. In L. Weiskrantz (Ed.). Thought without language, 185-210. Oxford, London: Clarendon Press.

Leslie, A. M. (1994). ToMM, ToBy and agency. In L. A. Hirschfeld, \& S. A. Gelman (Eds.). Mapping the mind: 
Domain specificity in cognition and culture. MA: Cambridge University Press.

Levillain, F., \& Zibetti, E. (2012). Segmentation et perception intuitive dans la compréhension de l'action. Quels liens possibles? Proposition d'un niveau intermédiaire de représentation. L'Année Psychologique, 112(2), 277-308. doi:10.4074/S0003503312002059

Levillain, F., Zibetti, E., \& Lefort, S. (2016). Interpreting the behavior and interacting with non-anthropomorphic robotic artworks. International Journal of Social Robotics, 1-21. doi:10.1007/s12369-016-0381-8

Levitis, D. A., Lidicker, W. Z., Jr., \& Freund, G. (2009). Behavioural biologists do not agree on what constitutes behaviour. Animal Behaviour, 78(1), 103-110. doi:10.1016/j.anbehav.2009.03.018

MacDorman, K. F., \& Ishiguro, H. (2006). The uncanny advantage of using androids in cognitive and social science research. Interaction Studies, 7(3), 297-337. doi:10.1075/is.7.3.03mac

Markson, L., \& Spelke, E. S. (2006). Infants' rapid learning about self-propelled objects. Infancy, 9(1), 45-71. doi:10.1207/s15327078in0901_3

Mazzolai, B., Margheri, L., Cianchetti, M., Dario, P., \& Laschi, C. (2012). Soft-robotic arm inspired by the octopus: II. From artificial requirements to innovative technological solutions. Bioinspiration \& Biomimetics, 7(2), 025005. doi:10.1088/1748-3182/7/2/025005

Michotte, A. (1963). The perception of causality. New York: Basic Books.

Monroe, A. E., Dillon, K. D., \& Malle, B. F. (2014). Bringing free will down to Earth: People's psychological concept of free will and its role in moral judgment. Consciousness and cognition, 27, 100-108. doi:10.1016/j.concog.2014.04.011

Montague, R. P. (2008). Free will. Current Biology, 18, R584-R585.

Montgomery, D. E., \& Montgomery, D. A. (2010). The influence of movement and outcome on young children's attributions of intention. British Journal of Developmental Psychology, 17(2), 245-261. doi:10.1348/026151099165258

Mori, M. (1970). The uncanny valley. Energy, 7(4), 33-35.

Morris, M. W., \& Peng, K. (1994). Culture and cause: American and Chinese attributions for social and physical events. Journal of Personality and Social Psychology, 67(6), 949-971. doi:10.1037/0022-3514.67.6.949

Nass, C., \& Moon, Y. (2000). Machines and mindlessness: Social responses to computers. Journal of Social Issues, 56 (1), 81-103. doi:10.1111/0022-4537.00153

Norman, D. A. (1990). The design of everyday things. New York: Doubleday Currency.

Norman, D. A. (1999). Affordances, conventions and design. Interactions, 6(3), 38-43.

Norman, D. A. (2007). Emotional design: Why we love (or hate) everyday things. New York: Basic Books.

Norman, D. A. (2010). Living with Complexity. MA: MIT Press.

Opfer, J. E. (2002). Identifying living and sentient kinds from dynamic information: The case of goal-directed versus aimless autonomous movement in conceptual change. Cognition, 86(2), 97-122.

Persson, P., Laaksolahti, J., \& Lönnqvist, P. (2000). Anthropomorphism: A multi-layered phenomenon. Technical Report FS-00-04, American Association for Artificial Intelligence (AAAI).

Piaget, J. (1929). The child's conception of the world. New York: Harcourt.

Poulin-Dubois, D., Lepage, A., \& Ferland, D. (1996). Infants' concept of animacy. Cognitive Development, 11(1), 19-36. doi:10.1016/s0885-2014(96)90026-x

Premack, D. (1990). The infant's theory of self-propelled objects. Cognition, 36(1), 1-16.

Reeves, B., \& Nass, C. (1996). The media equation: How people treat computers, television, and new media like real people and places. MA: CSLI Publications and Cambridge University Press.

Rogers, Y., Sharp, H. \& Preece, J. (2015). Interaction design: Beyond human-computer interaction (4th ed.). Wiley: Hoboken, NJ. 
Levillain and Zibetti, Behavioral Objects

Rosenthal-von der Pütten, A. M., \& Krämer, N. C. (2015). Individuals' evaluations of and attitudes towards potentially uncanny robots. International Journal of Social Robotics, 7(5), 799-824. doi:10.1007/s12369015-0321-z

Ruijten, P. A. M., Bouten, D. H. L., Rouschop, D. C. J., Ham, J., \& Midden, C. J. H. (2014). Introducing a Raschtype anthropomorphism scale. In Proceedings of 2014 ACM/IEEE International Conference on HumanRobot Interaction (HRI) 280-281. New York: ACM. doi:10.1145/2559636.2559825

Salem, M., Eyssel, F., Rohlfing, K., Kopp, S., \& Joublin, F. (2013). To err is human(-like): Effects of robot gesture on perceived anthropomorphism and likability. International Journal of Social Robotics, 5(3), 313-323. doi:10.1007/s12369-013-0196-9

Salem, M., Lakatos, G., \& Amirabdollahian, F. (2015). Would you trust a (faulty) robot?: Effects of error, task type and personality on human-robot cooperation and trust. In Proceedings of the 10th Annual ACM/IEEE International Conference on Human-Robot Interaction (HRI), 141-148.

Saygin, A. P., Chaminade, T., Ishiguro, H., Driver, J., \& Frith, C. (2012). The thing that should not be: predictive coding and the uncanny valley in perceiving human and humanoid robot actions. Social Cognitive and Affective Neuroscience, 7(4), 413-422. doi:10.1093/scan/nsr025

Scholl, B. J., \& Gao, T. (2013). Perceiving animacy and intentionality: Visual processing or higher-level judgment? In M. D. Rutherford, \& V. A. Kuhlmeier (Eds.). Social perception detection and interpretation of animacy, agency, and intention, 197-230. MA: MIT Press.

Scholl, B. J., \& Tremoulet, P. D. (2000). Perceptual causality and animacy. Trends in Cognitive Sciences, 4(8), 299-309.

Sengers, P., \& Gaver, B. (2006). Staying open to interpretation: Engaging multiple meanings in design and evaluation. In Proceedings of the 6th Conference on Designing Interactive Systems (DIS), 99-108. doi:10.1145/1142405.1142422

Sloman, S., \& Malt, B. (2003). Artifacts are not ascribed essences, nor are they treated as belonging to kinds. Language and Cognitive Processes, 18(5-6), 563-582. doi:10.1080/01690960344000035

Severson, R. L., \& Carlson, S. M. (2010). Behaving as or behaving as if? Children's conceptions of personified robots and the emergence of a new ontological category. Neural Networks, Special Issue on Social Cognition: From Babies to Robots, 23, 1099-1103. doi:10.1016/j.neunet.2010.08.014

Suchman, L. A. (1986). Plans and situated actions: The problem of human-machine communication. New York: Cambridge University.

Sung, J.-Y., Guo, L., Grinter, R. E., \& Christensen, H. I. (2007). "My Roomba is Rambo": Intimate home appliances. In UbiComp 2007: Ubiquitous Computing (Vol. 4717, pp. 145-162). Berlin, Heidelberg: Springer Berlin-Heidelberg. doi:10.1007/978-3-540-74853-3_9

Tomasello, M. (1995). Joint attention as social cognition. In D. Moore, \& P. J. Dunham (Eds.). Joint attention: Its origins and role in development, 103-130. NJ: Lawrence Erlbaum Associates, Hillsdale.

Trauble, B., Pauen, S., \& Poulin-Dubois, D. (2014). Speed and direction changes induce the perception of animacy in 7-month-old infants. Frontiers in Psychology, 5, 1141. doi:10.3389/fpsyg.2014.01141

Tremoulet, P. D., \& Feldman, J. (2000). Perception of animacy from the motion of a single object. Perception, 29(8), 943-951. doi:10.1068/p3101

Tremoulet, P. D., \& Feldman, J. (2006). The influence of spatial context and the role of intentionality in the interpretation of animacy from motion. Perception and Psychophysics, 68(6), 1047-1058.

Van den Brule, R., Dotsch, R., Bijlstra, G., Wigboldus, D. H. J., \& Haselager, P. (2014). Do robot performance and behavioral style affect human trust? International Journal of Social Robotics, 6(4), 519-531. doi:10.1007/s12369-014-0231-5

Von der Pütten, A. M., Krämer, N. C., Gratch, J., \& Kang, S. H. (2010). "It doesn't matter what you are!" Explaining social effects of agents and avatars. Computers in Human Behavior, 26(6), 1641-1650. doi:10.1016/j.chb.2010.06.012 
Wallace, R. A., Sanders, G. P., \& Feri, R. J. (1991). Biology: The science of life (3rd ed.). New York: Harper.

Wright, P., \& McCarthy, J. (2008). Empathy and experience in HCI. In Proceedings of the Conference on Human Factors in Computing Systems (SIGCHI), 637-646. doi:10.1145/1357054.1357156

Zacks, J. M., Speer, N. K., Swallow, K. M., Braver, T. S., \& Reynolds, J. R. (2007). Event perception: A mind-brain perspective. Psychological Bulletin, 133(2), 273-293. doi:10.1037/0033-2909.133.2.273.

Zawieska, K., Duffy, B. R., \& Strońska, A. (2012). Understanding anthropomorphisation in social robotics. Pomiary Automatyka Robotyka, 16(11), 78-82.

F. Levillain, Laboratoire CHART-LUTIN (Cognition Humaine \& Artificielle EA 4004, Université Paris 8, EPHE Paris; Cité des Sciences et de l'Industrie, Paris), Saint Denis - Cedex 02, France. Email: flevillain@mac.com; E. Zibetti, Laboratoire CHART-LUTIN (Cognition Humaine \& Artificielle EA 4004, Université Paris 8, EPHE Paris; Cité des Sciences et de l'Industrie, Paris), Saint Denis - Cedex 02, France. Email: ezibetti@univ-paris8.fr 